Case Report

\title{
Acute Severe Hyponatremia following Hysteroscopic Procedure in a Young Patient: A Case Report and Review of the Literature
}

\author{
Anwar S. Atieh $\mathbb{D D}^{1}{ }^{1}$ Omar K. Abu Shamma ${ }^{\mathbb{D}},{ }^{1}$ Mohammad O. Abdelhafez $\left(\mathbb{D},{ }^{1}\right.$ \\ Muath A. Baniowda $\left(D,{ }^{1}\right.$ Samia Abed, ${ }^{1}$ Basheer H. Babaa $\left(D,{ }^{1}\right.$ Abdurrahman Hamadah, ${ }^{2}$ \\ and Kamel A. Gharaibeh (iD ${ }^{1}$ \\ ${ }^{1}$ Al-Quds University, Faculty of Medicine, Jerusalem, State of Palestine \\ ${ }^{2}$ Hashemite University, Faculty of Medicine, Zarqa, Jordan
}

Correspondence should be addressed to Anwar S. Atieh; anwar.5994@yahoo.com

Received 9 July 2021; Accepted 2 September 2021; Published 21 September 2021

Academic Editor: Anja Haase-Fielitz

Copyright $\odot 2021$ Anwar S. Atieh et al. This is an open access article distributed under the Creative Commons Attribution License, which permits unrestricted use, distribution, and reproduction in any medium, provided the original work is properly cited.

Background. Hysteroscopic surgery is a minimally invasive procedure used to diagnose and treat intrauterine pathologies. It requires distension of the uterine cavity for the adequate visualization of the operative field. Glycine (1.5\%) is one of the most commonly used solutions because it is nonconductive and also has good optical properties. However, acute hyponatremia is a critical complication that can develop after the absorption of a sufficient amount of the irrigation medium. Case Presentation. We report a case of a 43 -year-old female patient who developed acute symptomatic hyponatremia $(104 \mathrm{mEq} / \mathrm{L})$ and pulmonary edema secondary to hysteroscopic resection of leiomyoma and hastily approached with rapid sodium correction measures. Conclusion. Multiple strategies can be taken to reduce the risk of fluid absorption and subsequent hyponatremia. Moreover, attention should be paid to the treatment approach for patients with acute hyponatremia following hysteroscopic procedures; rapid correction of acute hyponatremia for such patients might be safe, although there is no consensus in the literature, and further trials are needed.

\section{Background}

Hysteroscopy has implemented a minimally invasive procedure for treating and diagnosing intrauterine pathology. A uterine distending medium is used to allow an optimal and global view of the endometrial cavity. Nonconductive (i.e., nonelectrolyte) and conductive solutions are widely used as a distension medium for hysteroscopic procedures. Glycine is one of the most commonly used irrigation fluids in hysteroscopy; it is a hypoosmotic solution compared to serum osmolality, and it has an osmolality of $200 \mathrm{mosmol} / \mathrm{kg}$ [1].

Complications from hysteroscopy are rare, with a reported rate of $0.22 \%$. Hyponatremia and fluid overload are considered as feared but rare complications of hysteroscopy; according to a multicenter study of over 21,000 operative hysteroscopic procedures, the incidence rate of fluid overload and hyponatremia is $0.06 \%$ [2]. The volume of medium absorbed, which is measured by volume deficit, is the most significant risk factor for the development of hyponatremia, and it has a direct relationship with the degree of hyponatremia [3].

Patients with acute hyponatremia due to hysteroscopy can be asymptomatic. They can also have variable symptoms, such as nausea, vomiting, confusion, and convulsions, depending on the severity of hyponatremia and irrigant absorption rate. Furthermore, the use of general anesthesia can also conceal the symptoms of hyponatremia [4-6].

Hyponatremia in hysteroscopic procedures has been reported with the use of $1.5 \%$ glycine, $3 \%$ sorbitol, $5 \%$ mannitol, and $5 \%$ dextrose which are the major nonconductive (i.e., nonelectrolyte) irrigation and distension fluids [7-10]. 
A number of factors should be considered when selecting distention media for hysteroscopy, including the procedure to be performed and the instruments to be used. The traditional electrosurgery devices have a monopolar design and can be only used with electrolyte-free irrigation fluids [11]. However, bipolar electrosurgery devices are now more widely used.

Here, we report on a patient undergoing a hysteroscopic removal of leiomyoma with an endometrial ablation, who developed acute symptomatic hyponatremia $(104 \mathrm{mEq} / \mathrm{L})$ due to the irrigation fluid (1.5\% glycine).

\section{Case Presentation}

A 43-year-old woman (weight, $70 \mathrm{~kg}$ ) presented with a history of 7-month duration of intermittent and prolonged vaginal bleeding. A physical examination and an ultrasound showed a submucosal leiomyoma that protruded into the uterine cavity. There were no other symptoms or pathological findings. The patient had a free past medical and surgical history. She had no known allergies. She was taking daily doses of ethinyl estradiol $(0.03 \mathrm{mg})$ and drospirenone (3 mg) continuously over 3 months and iron bisglycinate (36 mg) over the same period. The patient was offered scheduled hysteroscopic removal of the leiomyoma, and an endometrial ablation under general anesthesia (GA) was decided on, after which the patient gave written informed consent.

Preoperative laboratory findings, which included a complete blood exam (CBC), electrolytes analyses, coagulation parameters, showed anemia with hemoglobin of $7.5 \mathrm{~g} /$ $\mathrm{dL}$, and a 12-lead electrocardiogram (ECG) showing sinus tachycardia. Most notably, both creatinine and sodium were within normal levels, that is, $1.1 \mathrm{mg} / \mathrm{dL}$ and $139 \mathrm{mEq} / \mathrm{L}$, respectively. Upon arrival at the operating room, the patient was placed in the lithotomy position followed by the application of a peripheral venous catheter and standard monitoring devices (ECG, noninvasive blood pressure cuff (NIBP), and pulse oximetry $\left.\left(\mathrm{SpO}_{2}\right)\right)$. Immediately before the anesthesia induction, vital signs were blood pressure 104/ $69 \mathrm{mmHg}$, heart rate 107 beats/min, pulse oximetry revealed $100 \%$ of $\mathrm{SpO}_{2}$, and temperature of $37.6^{\circ} \mathrm{C}$ before anesthetic induction; general anesthesia was induced intravenously with propofol and sufentanil. An endotracheal tube (ETT) was facilitated with rocuronium, and after the correct positioning was verified, the lungs were ventilated with a fraction of inspired oxygen $\left(\mathrm{FiO}_{2}\right)$ of 0.5 and a minute volume (MV) of $74 \mathrm{~mL} / \mathrm{min} / \mathrm{kg}$. After anesthesiological clearance, the hysteroscopy commenced, dilation was done by Hegar dilator till \#9. Anesthesia was maintained with continuous infusion of propofol. Glycine (1.5\%) solution was used as the distension medium. This standard hypotonic solution contains $1.5 \mathrm{~g}$ glycine per $100 \mathrm{~mL}$ of water and has an osmolality of 200. A pressure of $120 \mathrm{mmHg}$ was applied to unfold the uterine cavity. Endometrial ablation and dissection of a $2.5 * 3 * 3 \mathrm{~cm}$ submucosal fundal myoma were performed within $20 \mathrm{~min}$ by monopolar resection. The patient remained in a hemodynamically stable condition throughout the procedure.
The ET tube was removed, and the patient was immediately sent to the recovery area. Upon recovery, the $\mathrm{SpO}_{2}$ level suddenly fell from $98 \%$ to $80 \%$ to $85 \%$, and supplemental $\mathrm{O}_{2}$ at a rate of 3 liters per minute by nasal cannula was applied and immediately treated with $20 \mathrm{mg}$ of furosemide. Her chest auscultation was clear with a good air entry bilateral, and her blood pressure was 134/72, $\mathrm{SpO}_{2}$ $90 \%$, and pulse of 56 beats per minute $(\mathrm{b} / \mathrm{m})$, abdominal ultrasound was free, and vaginal examination revealed no active bleeding. The bladder was catheterized, with a urine output of $2500 \mathrm{~mL}$ for a duration of $30 \mathrm{mins}$, and the patient was sent to the gynecological ward. Five minutes later, the patient showed desaturation of $\mathrm{SpO}_{2} 85 \%$, became drossy, and developed blurred vision. Supplemental $\mathrm{O}_{2}$ at a rate of 5 Liters per minute by face mask was applied, $20 \mathrm{mg}$ of furosemide was given, and blood tests and electrolyte analyses indicated a drop of hemoglobin to $6 \mathrm{~g} / \mathrm{dL}$ and hyponatremia (Na $104 \mathrm{mEq} / \mathrm{L})$. About $500 \mathrm{~mL}$ of $3 \%$ saline solution was immediately administered at an infusion rate of $500 \mathrm{~mL} / \mathrm{h}$ and 2 units of PRBCs were given with precisely monitoring for electrolyte changes every hour. Meanwhile, the patient started complaining of headaches, nausea, and vomiting. One hour later, serum electrolyte analyses showed an elevation of $\mathrm{Na}$ level to 118 . The order was given to switch fluids to normal saline with a rate of $100 \mathrm{cc} / \mathrm{h}$, repeat serum analysis every hour, and do a neurological exam every 30 minutes. Plasma sodium levels increased to $119 \mathrm{mEq} / \mathrm{L}$ after $1 \mathrm{~h}$ and to $134 \mathrm{mEq} / \mathrm{L}$ after $6 \mathrm{~h}$, as shown in Table 1 .

The neurological assessment revealed no detectable deficits, and symptoms were revealed except for a headache. 12 hours after the onset of hyponatremia, the patient was off oxygen, and $\mathrm{SpO}_{2}$ was $98 \%$ on room air, no complaints, and sodium level was within normal ( $\mathrm{Na} 135 \mathrm{mEq} / \mathrm{L})$. Until then, the cumulative renal excretion was $8.5 \mathrm{~L}$. 9 liters of distension medium was used intraoperatively with a calculated uptake of $4 \mathrm{~L}$. A sample was not obtained for serum osmolarity determination. The patient recovered uneventfully and was discharged from the hospital on the second postoperative day. During a 6-month follow-up, the patient remained asymptomatic with no neurologic complications.

\section{Discussion}

Fluid overload and hyponatremia are life-threatening complications associated with the use of nonconductive hypoosomolar distension media in hysteroscopy. Sufficient absorption of solutions like $1.5 \%$ glycine, $3 \%$ sorbitol, and $5 \%$ mannitol is more associated with dilutional hyponatremia, whereas using isotonic normal saline is associated with fluid overload [12]. Fluid absorption into the vascular space (intravasation) is the central underlying mechanism for fluid overload and hyponatremia problems. The main driving force for intravasation is the distension media pressure. In 250 operative hysteroscopies, there was no significant fluid absorption when keeping the intrauterine pressure below $80 \mathrm{mmHg}$ [13]. Furthermore, procedures that invade the myometrium expose the uterine vascular system, which increases the potential for fluid intravasation [14]. 
TABLE 1: The patient's electrolyte data.

\begin{tabular}{lcc}
\hline & $\begin{array}{c}\text { Sodium } \\
(\mathrm{mEq} / \mathrm{L})\end{array}$ & $\begin{array}{c}\text { Potassium } \\
(\mathrm{mEq} / \mathrm{L})\end{array}$ \\
\hline $\begin{array}{l}\text { Preoperatively } \\
\quad \text { Before the procedure }\end{array}$ & 139 & 3.8 \\
\hline $\begin{array}{l}\text { Postoperatively } \\
\text { 10 minutes after the procedure }\end{array}$ & 104 & \\
1 hour & 118 & 3.5 \\
2 hours & 119 & 3.7 \\
8 hours & 134 & 3.7 \\
12 hours & 135 & 3.5 \\
\hline
\end{tabular}

The data regarding the rule of type of anesthesia on fluid absorption are conflicting; a randomized prospective comparative study by Goldenberg et al. found that fluid absorption is significantly higher with hysteroscopies done by epidural anesthesia when compared to general anesthesia. They hypothesized that epidural anesthesia causes vasodilation of the pelvic vessels, a consequence caused by the known effect of epidural anesthesia in sympathetic blocking $[15,16]$. Conversely, Goldenberg et al. did not study the impact of local anesthesia with intravenous sedation on fluid distention media absorption. On the contrary, a retrospective cohort study by Bergeron et al. found that fluid absorption was the highest with general anesthesia and the lowest when using local anesthesia with intravenous sedation, they believe that inhaled anesthetics used in general anesthesia have a potent effect on the absorption of glycine. Inhaled anesthetics dilate arteriolar muscles, thus inducing vasodilatation, which leads to the intravasation of distension fluid. Moreover, a higher rate of glycine fluid absorption and a more rapid decrease in serum sodium concentration were associated with general anesthesia. Thus, they recommend considering regional anesthesia with sedation for hysteroscopic procedures using glycine as a distension medium $[17,18]$.

In a randomized trial of 33 women who had a hysteroscopic endometrial ablation, administration of intracervical vasopressin solution $(0.05 \mathrm{U} / \mathrm{mL})$ was associated with a significant decrease in plasma glycine concentration but a small nonsignificant reduction of dilutional hyponatremia [19]. In another small prospective series comprising 36 patients, who underwent transurethral resection of the prostate (TURP), the use of intraprostatic vasopressin has possible protection against hyponatremia. They presume that vasopressin constricts the prostatic blood vessels and reduces bleeding, which in turn enhances the visibility of the prostatic capsule and allows early identification of capsular tear, as well it could decrease irrigant fluid absorption [20]. In another prospective controlled study, 88 patients underwent hysteroscopic procedures. They used general anesthesia in 62 cases (control group), whereas spinal anesthesia combined with oxytocin infusion was used in the other 26 cases (study group). They presumed that using low-dose oxytocin (10 international units (IUs) in $200 \mathrm{~mL}$ normal saline) would stimulate uterine contractions compressing the myometrial vessels and reduce the glycine absorption. There was a statistically significant less mean fluid deficit in the study group than the control group in endometrial polypectomy and myomectomy patients but not in those who underwent septal resection [21].

The $1.5 \%$ glycine is one of the most common solutions used in monopolar hysteroscopic procedures due to its nonhemolytic, nonconductive, and transparent properties, although it is more toxic and has poorer outcomes when confronted with other options [22]. The absorption of glycine solution into the extracellular space will make the blood hypertonic with a higher volume, which will draw the fluid outside the cells. Both events, in turn, will cause hyponatremia due to the dilutional effect. A few hours later, the glycine will be absorbed by cells and metabolized into ammonia [23].

The severity of hyponatremia is highly connected to the volume deficit of the glycine solution; a volume deficit of $1000 \mathrm{~mL}$ will reduce sodium concentration in the plasma by $10 \mathrm{mEq} / \mathrm{L}$ [3]. An excessive amount of fluid absorption is not only associated with hyponatremia; it may develop to cause pulmonary edema that can present with hypoxia and shortness of breath [24].

Moderate to severe hyponatremia, associated with glycine irrigant absorption, can cause many serious neurological symptoms like seizures, confusion, coma, and visual disturbances [25]. Visual disturbances were linked to the glycine inhibitory effect on retinal cells [26]. However, hyponatremic encephalopathy does not have a specific neurologic presentation but is mainly present with headache, nausea, and vomiting [27]. The severity of these complications determined mainly by the presence of cerebral edema and hypoosmolality [28]. Most publications reported neurological or respiratory presenting symptoms as a complication of hyponatremia or fluid overload associated with hysteroscopic procedures as shown in Table 2. Ayus-Arieff syndrome is a common but unrecognized complication of severe hyponatremia where cerebral edema drives neurogenic pulmonary edema. This phenomenon was noticed among healthy marathon runners who presented with hyponatremia secondary to dehydration and developed pulmonary edema that frequently requires mechanical ventilation [29]. The underlying mechanism of this syndrome is that cerebral edema leads to increased intracranial pressure, leading to centrally mediated increases in catecholamine release and capillary injury. The pulmonary vasculature seems to be the most affected. In addition, pulmonary artery hypertension and plasma leakage through the injured capillaries cause pulmonary edema and, as a sequel, acute respiratory distress syndrome [30]. For our presented patient, rapid correction of the hyponatremia led to clearing the cerebral edema and, consequently, neurogenic pulmonary edema.

Hyponatremia caused by using glycine solution has a less pronounced fall in the measured plasma osmolality due to the presence of osmotically active particles of glycine in extracellular space. Although there is a modest reduction in serum osmolality, yet marked neurologic symptoms still occur $[23,44]$. This can be explained by the presence of ammonia as a secondary metabolite of glycine and the toxicity from glycine itself since it has a neuroinhibitory 


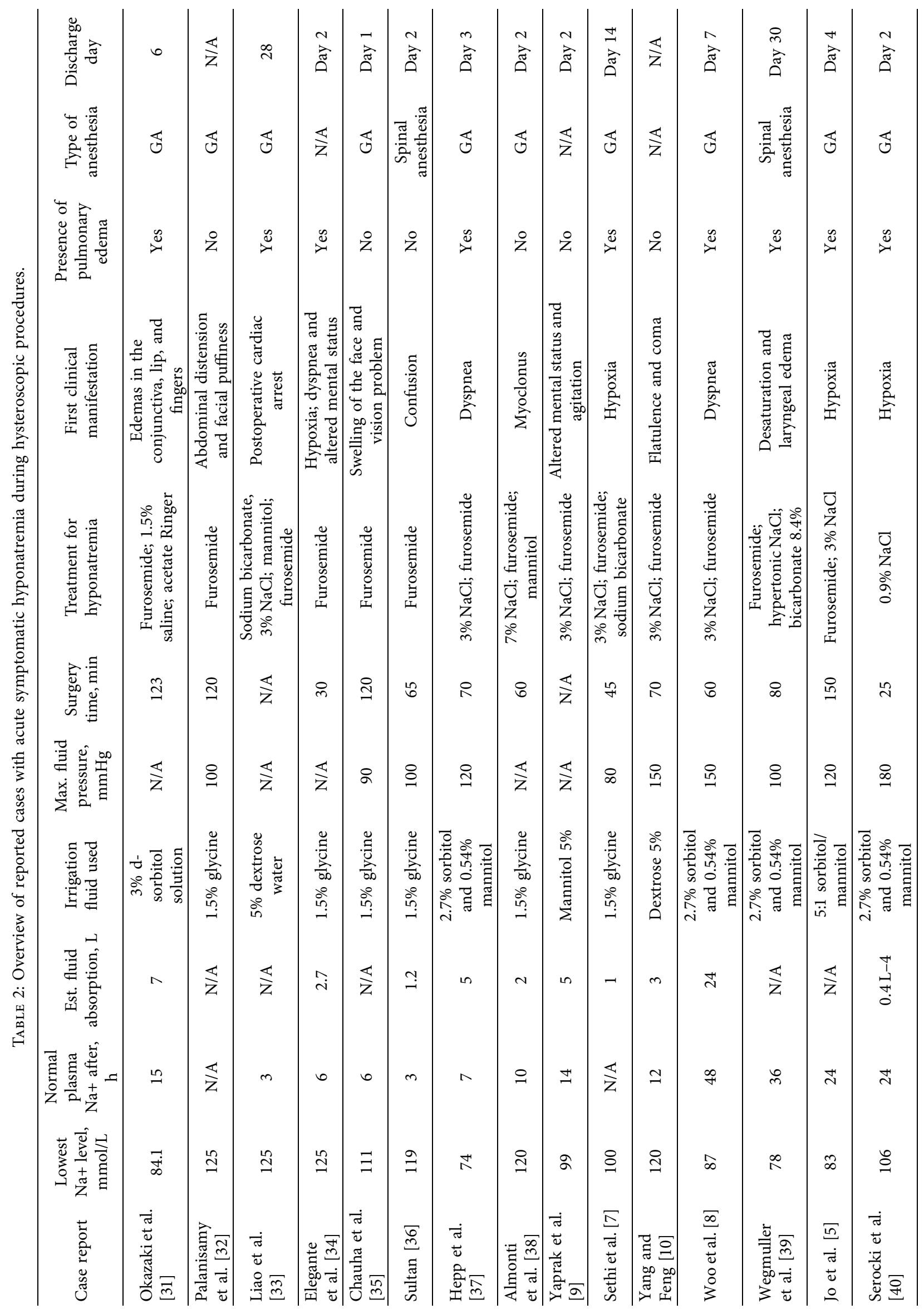




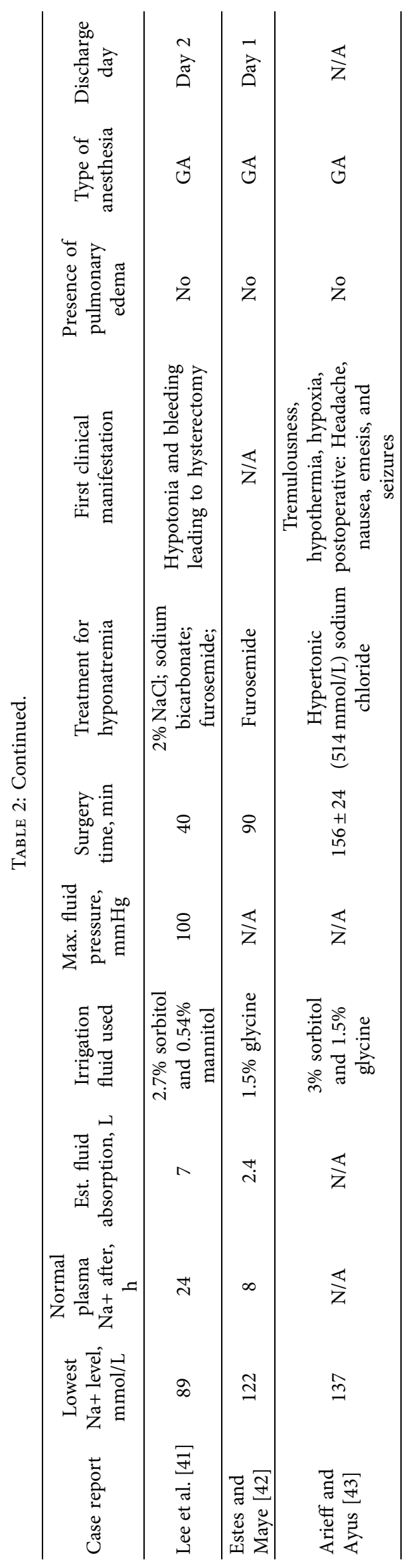


effect on the central nervous system [26, 45]. Also, it is found that cerebral edema was more frequent in premenopausal women, which could be attributed to the suppression of $\mathrm{Na}+/ \mathrm{K}+$ ATPase pump caused by female sex steroids; these pumps normally decrease the risk of cerebral edema caused by hyponatremia [27].

It is well established that distending media containing electrolytes urge the use of bipolar resectoscope instruments. These newer devices are compatible with electrolyte-containing irrigation and distension solutions such as isotonic saline and Ringer's lactate. The use of isotonic saline or Ringer's lactate solutions as a distension medium is not associated with hyponatremia or hypoosmolality $[1,46]$. On the contrary, the use of monopolar instrumentation requires electrolyte-free solutions such as $5 \%$ mannitol, $1.5 \%$ glycine, and $3 \%$ sorbitol, to facilitate the completion of the radiofrequency electrical circuit [47]. Hence, hyponatremia should always be considered following a unipolar hysteroscopic procedure. Multiple measures can be taken to avoid it. Replacement of unipolar electrosurgery by bipolar significantly reduces the risk. A meta-analysis study showed sodium mean decrease of $1.5 \mathrm{mEq} / \mathrm{L}$ when using bipolar electrosurgery comparing to unipolar electrosurgery $(5.1 \mathrm{mEq} / \mathrm{L})[48,49]$. Furthermore, reduction of the procedure time is an important factor for the development of hyponatremia since longer procedure duration is associated with a higher absorption deficit. The American College of Obstetricians and Gynecologists (ACOG) suggests to temporarily halt the procedure after $750 \mathrm{~mL}$ absorption deficit and termination of the procedure if the deficit exceeds $1000 \mathrm{~mL}$ [49]. Careful monitoring of fluid in and out during the hysteroscopy will help the surgeon determine when to stop the procedure before excessive fluid absorption elicits a symptomatic hyponatremia or fluid overload [37].

The treatment of excessive fluid absorption and subsequent hyponatremia depends on the patient's clinical picture. Asymptomatic hyponatremia does not require any urgent intervention, whereas marked, symptomatic hyponatremia must be treated as quickly as possible to reduce the risk of complications. Rapid correction of acute hyponatremia is probably safe, as the cerebral adaptation needs time to take place [50]. Based on Ayus et al. study, rapid infusion of hypertonic saline is recommended for correcting severe acute hyponatremia [23], and our patient was managed accordingly. However, her sodium level rapidly increased from $104 \mathrm{mEq} / \mathrm{L}$ to $118 \mathrm{mEq} / \mathrm{L}$ in 1 h. A series study of 64 hyponatremic encephalopathy patients presented to the emergency department was treated with a continuous intravenous infusion of $500 \mathrm{~mL}$ of $3 \%$ sodium chloride solution over $6 \mathrm{~h}$. Although 12 deaths were reported, all of which were recorded after the resolution of hyponatremic encephalopathy and were postulated to comorbid conditions, $75 \%$ of deaths were related to sepsis. They concluded that $3 \%$ sodium chloride solution was effective in reversing neurologic symptoms, and clinical evidence of cerebral demyelination, permanent neurologic injury, or death within 6 months posttreatment follow-up [51].
Unfortunately, there is no evidence from controlled trials, as to what the best or optimal correction rate is in acute hyponatremia following hysteroscopic procedures.

Nevertheless, ACOG guidelines recommended that the serum sodium level should not be raised more than $12 \mathrm{mEq} /$ $\mathrm{L}$ in the first $24 \mathrm{~h}$ with strict monitoring; to prevent reaching normal or hypernatremic levels [52-54]. ACOG also concluded that the rate of correction should be slower $(8-10 \mathrm{mEq} / \mathrm{L}$ maximum increase in the first $24 \mathrm{~h})$ in patients who present with hyponatremia more than $48 \mathrm{~h}$ after the procedure [54]. A hypertonic saline infusion may play a substantial role by reduction of cerebral edema and replacement of sodium. A series of 18 patients underwent TURP or hysteroscopy; Fourteen of them developed hyponatremia, they were treated supportively, and received hypertonic saline. They survived without long-term sequelae. Two males suffered respiratory arrest as the initial clinical manifestation of hyponatremic encephalopathy; both patients died and did not receive hypertonic saline. Two other female patients, who did not survive, recovered from anesthesia but had nausea, emesis, and headache, and both experienced respiratory arrests. After the respiratory arrest, their serum sodium levels were 125 and $120 \mathrm{mmol} / \mathrm{L}$; both patients died, and autopsies revealed cerebral edema with tonsillar herniation. However, the degree of hyponatremia or the amount of fluid retention was not the determinant factor for the four deaths. This retrospective study cannot be conclusive, and other factors might play a role in determining morbidity and mortality [23].

When the hyponatremia is associated with a relatively normal measured serum osmolality, in such cases where glycine remains confined to the extracellular fluid, hemodialysis should be considered since hypertonic saline therapy is associated with an increased risk of pontine myelinolysis. Hemodialysis showed to safely stabilize the patients and correct the electrolyte and fluid disturbances, and it gives the benefits of correcting the hyponatremia while eliminating the unmeasured solute $[14,44]$. Indeed, it is hard to control the correction rate, and it is often more rapid than expected. In our case, the patient received a total of $500 \mathrm{~mL}$ of $3 \%$ hypertonic saline in $1 \mathrm{~h}$. The correction rate for hyponatremia was faster than expected, and the serum sodium level spontaneously increased to $135 \mathrm{mEq} / \mathrm{L}$ within $14 \mathrm{~h}$. She recovered uneventfully and remained asymptomatic with no neurologic complications after 6 month on follow-up. Our presented case is in agreement with a number of reported cases that have shown severe hyponatremia during hysteroscopic procedures, provided in Table 2. None of these publications reported a detrimental effect associated with the rapid correction of hyponatremia. Furthermore, all patients recovered fully, even in cases with very low sodium levels.

\section{Conclusion}

The systemic absorption of distending medium used in hysteroscopic producers can have multiple complications, of which acute hyponatremia can have severe consequences. Therefore, multiple measures can be taken to avoid those complications. Using electrolyte-based distending media 
instead of hypoosmolar solutions significantly reduces the risk. In addition, attention should be on reducing and precisely monitoring fluid intake. Furthermore, some studies have focused on the role of anesthetic technique on fluid absorption, using local anesthesia instead of other types, combining intravenous oxytocin infusion with spinal anesthesia, or the concomitant use of intrauterine vasopressin revealed promising protection against volume overload and hyponatremia. Future randomized trials ought to focus on the impact of anesthesia and such medications on developing hyponatremia. Besides, we should review the role and the outcome of rapid correction of acute hyponatremia in such cases, since anecdotal reports are not in line with the literature regarding developing osmotic demyelinating syndrome. Conclusively, our case supports the advantage of the rapid correction of acute hyponatremia.

\section{Data Availability}

The plasma sodium level data used to support the findings of this study are included within the article. Any further data are available from the corresponding author upon request.

\section{Ethical Approval}

This case report was carried out in accordance with the research protocol that was approved by the Al-Quds University Research Ethics Committee.

\section{Consent}

Written informed consent was obtained from the patient in accordance with the Declaration of Helsinki.

\section{Conflicts of Interest}

The authors declare that they have no conflicts of interest.

\section{Authors' Contributions}

A. A., O. A., M. A., and M. B. were responsible for conception and study design, data collection, interpretation of data, and manuscript writing. S. A., B. B., A. H., and K. G. have been involved in drafting the manuscript and revising it critically for important intellectual content. All authors read and approved the final manuscript.

\section{Acknowledgments}

The authors thank the patient for giving her consent for publication of this case. They thank Dr. Amal Musleh for doing the procedure. They thank Dr. Mohammad Jaradat for his contribution to the treatment of the patient. They thank the surgical team in the Red Crescent hospital.

\section{References}

[1] S. Umranikar, T. J. Clark, E. Saridogan et al., "BSGE/ESGE guideline on management of fluid distension media in operative hysteroscopy," Gynecological Surgery, vol. 13, no. 4, pp. 289-303, 2016.
[2] B. Aydeniz, I. V. Gruber, B. Schauf, R. Kurek, A. Meyer, and D. Wallwiener, "A multicenter survey of complications associated with 21676 operative hysteroscopies," European Journal of Obstetrics and Gynecology Reproductive Biology, vol. 104, pp. 160-164, 2002.

[3] O. Istre, K. Skajaa, A. P. Schjoensby, and A. Forman, "Changes in serum electrolytes after transcervical resection of endometrium and submucous fibroids with use of glycine $1,5 \%$ for uterine irrigation," Obstetrics and Gynecology, vol. 80, pp. 218-222, 1992.

[4] C. A. Witz, K. M. Silverberg, W. N. Burns, R. S. Schenken, and D. L. Olive, "Complications associated with the absorption of hysteroscopic fluid media," Fertility and Sterility, vol. 60, pp. 745-756, 1993.

[5] Y. Y. Jo, H. J. Jeon, E. Choi, and Y. S. Choi, "Extreme hyponatremia with moderate metabolic acidosis during hysteroscopic myomectomy -a case report-," Korean Journal of Anesthesiology, vol. 60, no. 6, p. 440, 2011.

[6] I. Demirel, A. B. Ozer, M. K. Bayar, and O. L. Erhan, "TURP syndrome and severe hyponatremia under general anaesthesia," BMJ Case Reports, vol. 2012, 2012.

[7] N. Sethi, K. Kumar, and R. Chaturvedi, "Operative hysteroscopy intravascular absorption syndrome: a bolt from the blue," Indian Journal of Anaesthesia, vol. 56, no. 2, p. 179, 2012.

[8] Y. C. Woo, H. Kang, S. M. Cha et al., "Severe intraoperative hyponatremia associated with the absorption of irrigation fluid during hysteroscopic myomectomy: a case report," Journal of Clinical Anesthesia, vol. 23, no. 8, pp. 649-652, 2011.

[9] M. Yaprak, M. N. Turan, A. F. Tamer et al., "How quickly can acute symptomatic hyponatremia be corrected?" International Urology and Nephrology, vol. 45, no. 6, pp. 1805-1808, 2013.

[10] B. J. Yang and L. M. Feng, "Symptomatic hyponatremia and hyperglycemia complicating hysteroscopic resection of intrauterine adhesion: a case report," Chinese Medical Journal, vol. 125, 2012.

[11] M. H. Goldrath, "Hysteroscopic endometrial ablation," Obstetrics and Gynecology Clinics of North America, vol. 22, 1995.

[12] A. Berg, L. Sandvik, A. Langebrekke, and O. Istre, "A randomized trial comparing monopolar electrodes using glycine $1.5 \%$ with two different types of bipolar electrodes (TCRis, Versapoint) using saline, in hysteroscopic surgery," Fertility and Sterility, vol. 91, 2009.

[13] G. J. Shirk and R. J. Gimpelson, "Control of intrauterine fluid pressure during operative hysteroscopy," American Association Gynecologic Laparoscopists, vol. 1, 1994.

[14] R. Agarwal and M. Emmett, "The post-transurethral resection of prostate syndrome: therapeutic proposals," American Journal of Kidney Diseases, vol. 24, 1994.

[15] M. Goldenberg, S. B. Cohen, A. Etchin, S. Mashiach, and D. S. Seidman, "A randomized prospective comparative study of general versus epidural anesthesia for transcervical hysteroscopic endometrial resection," American Journal of $\mathrm{Ob}$ stetrics and Gynecology, vol. 184, no. 3, pp. 273-276, 2001.

[16] D. C. Warltier, J. A. Campagna, and C. Carter, "Clinical relevance of the Bezold-Jarisch reflex," Anesthesiology, vol. 98, no. 5, pp. 1250-1260, 2003.

[17] M. È. Bergeron, C. Beaudet, E. Bujold, C. Rhéaume, P. Ouellet, and P. Laberge, "Glycine absorption in operative hysteroscopy: the impact of anesthesia," American Journal of $\mathrm{Ob}$ stetrics and Gynecology, vol. 200, no. 3, pp. e1-331, 2009. 
[18] J. S. Dungan, P. Ouellet, E. Bujold et al., "The impact of anesthesia on glycine absorption in operative hysteroscopy: a randomized controlled trial," Anesthesia and Analgesia, vol. 113, 2011.

[19] M. Goldenberg, M. Zolti, D. Bider, A. Etchin, B. A. Sela, and D. S. Seidman, "The effect of intracervical vasopressin on the systemic absorption of glycine during hysteroscopic endometrial ablation," Obstetrics and Gynecology, vol. 87, 1996.

[20] D. P. Sharma and A. B. Harvey, "Does intraprostatic vasopressin prevent the transurethral resection syndrome?" BJU International, vol. 86, no. 3, pp. 223-226, 2000.

[21] N. Al-Husban, A. Aloweidi, and O. Ababneh, "The impact of spinal anesthesia and use of oxytocin on fluid absorption in patients undergoing operative hysteroscopy: results from a prospective controlled study," International Journal of Women's Health, vol. 12, pp. 359-367, 2020.

[22] R. G. Hahn, "Glycine 1.5\% for irrigation should be abandoned," Urologia Internationalis, vol. 91, 2013.

[23] J. C. Ayus and A. I. Arieff, "Glycine-induced hypo-osmolar hyponatremia," Archives of Internal Medicine, vol. 157, no. 2, pp. 223-226, 1997.

[24] G. Serocki, R. Hanss, M. Bauer, J. Scholz, and B. Bein, "The gynecological TURP syndrome: severe hyponatremia and pulmonary edema during hysteroscopy," Der Anaesthesist, vol. 58 , no. 1 , pp. 30-34, 2009.

[25] J. Olsson, A. Nilsson, and R. G. Hahn, "Symptoms of the transurethral resection syndrome using glycine as the Irrigant," Journal of Urology, vol. 154, 1995.

[26] A. Karci and Y. Erkin, "Transient blindness following hysteroscopy," Journal of International Medical Research, vol. 31, no. 2, pp. 152-155, 2003.

[27] J. C. Ayus, J. M. Wheeler, and A. I. Arieff, "Postoperative hyponatremic encephalopathy in menstruant women," $A n$ nals of Internal Medicine, vol. 117, no. 11, p. 891, 1992.

[28] O. Istre, J. Bjoennes, R. Naess, and K. Hornbaek, "Postoperative cerebral oedema after transcervical endometrial resection and uterine irrigation with $1.5 \%$ glycine," Lancet, vol. 344, 1994.

[29] J. C. Ayus, J. Varon, and A. I. Arieff, "Hyponatremia, cerebral edema, and noncardiogenic pulmonary edema in marathon runners," Annals of Internal Medicine, vol. 132, no. 9, pp. 711-714, 2000.

[30] J. C. Ayus and A. I. Arieff, "Pulmonary complications of hyponatremic encephalopathy. Noncardiogenic pulmonary edema and hypercapnic respiratory failure," Chest, vol. 107, no. 2, pp. 517-521, 1995.

[31] H. Okazaki, N. Miura, Y. Kashima et al., "Severe hyponatremia with seizures and confirmed mild brain edema by hysteroscopic myomectomy: a case report," JA Clinical Reports, vol. 6, no. 1, pp. 4-8, 2020.

[32] N. Palanisamy, M. Zachariah, and N. Mani, "Intraoperative water intoxication and hypothermia in a patient undergoing hysteroscopic submucosal fibroid resection," Journal of Current Research in Scientific Medicine, vol. 6, no. 1, p. 60, 2020.

[33] C. Y. Liao, C. H. Lo, M. X. Yu et al., "Life-threatening acute water intoxication in a woman undergoing hysteroscopic myomectomy: a case report and review of the literature," BMC Women's Health, vol. 20, no. 1, pp. 1-6, 2020.

[34] M. Elegante, J. Hamera, J. Xiao, and D. Berger, "Operative hysteroscopy intravascular absorption syndrome causing hyponatremia with associated cerebral and pulmonary edema," Clinical Practice and Cases in Emergency Medicine, vol. 3, no. 3, pp. 252-255, 2019.
[35] R. Chauhan, V. Ganesan, and A. Luthra, "Operative hysteroscopy intravascular absorption syndrome: the gynecological transurethral resection syndrome," Journal of Obstetric Anaesthesia and Critical Care, vol. 8, no. 2, p. 112, 2018.

[36] S. S. Sultan, "Combined hyponatremia and hypocalcemia after intravascular absorption of $1.5 \%$ glycine during operative hysteroscopy. a case report," Egyptian Journal of Anaesthesia, vol. 32, no. 3, pp. 443-446, 2016.

[37] P. Hepp, T. Jüttner, I. Beyer, T. Fehm, W. Janni, and E. Monaca, "Rapid correction of severe hyponatremia after hysteroscopic surgery-a case report," BMC Anesthesiology, vol. 15, no. 1, 2015.

[38] S. Almonti, A. M. Cipriani, V. Villani, and S. Rinalduzzi, "Reversible myoclonus in a patient undergoing transcervical hysteroscopic surgery," Neurological Sciences, vol. 34, no. 10, pp. 1815-1817, 2013.

[39] B. Wegmüller, K. Hug, C. Meier Buenzli, B. Yuen, M. Maggiorini, and A. Rudiger, "Life-threatening laryngeal edema and hyponatremia during hysteroscopy," Critical Care Research and Practice, vol. 2011, Article ID 140381, 4 pages, 2011.

[40] G. Serocki, R. Hanss, M. Bauer, J. Scholz, and B. Bein, "Das gynäkologische "TUR-syndrom": schwere hyponatriämie und lungenödem während operativer hysteroskopie," Der Anaesthesist, vol. 58, no. 1, pp. 30-34, 2009.

[41] G. Y. Lee, J. I. Han, and H. J. Heo, "Severe hypocalcemia caused by absorption of sorbitol-mannitol solution during hysteroscopy," Journal of Korean Medical Science, vol. 24, no. 3, pp. 532-534, 2009.

[42] C. M. Estes and J. P. Maye, "Severe intraoperative hyponatremia in a patient scheduled for elective hysteroscopy: a case report," AANA Journal, vol. 71, no. 3, pp. 203-205, 2003.

[43] A. I. Arieff and J. C. Ayus, "Endometrial ablation complicated by fatal hyponatremic encephalopathy," JAMA: The Journal of the American Medical Association, vol. 270, no. 10, pp. 1230-1232, 1993.

[44] H. T. Campbell, M. E. Fincher, and A. H. Sklar, "Severe hyponatremia without severe hypoosmolality following transurethral resection of the prostate (TURP) in end-stage renal disease," American Journal of Kidney Diseases, vol. 12, 1988.

[45] S. Sunderrajan, J. H. Bauer, R. L. Vopat, P. Wanner-Barjenbruch, and A. Hayes, "Posttransurethral prostatic resection hyponatremic syndrome: case report and review of the literature," American Journal of Kidney Diseases, vol. 4, 1984.

[46] A. M. Darwish, Z. Z. Hassan, A. M. Attia, S. S. Abdelraheem, and Y. M. Ahmed, "Biological effects of distension media in bipolar versus monopolar resectoscopic myomectomy: a randomized trial," Journal of Obstetrics and Gynaecology Research, vol. 36, no. 4, pp. 810-817, 2010.

[47] AAGL Advancing Minimally Invasive Gynecology Worldwide, M. G. Munro, K. Storz et al., "AAGL practice report: practice guidelines for the management of hysteroscopic distending media. (replaces hysteroscopic fluid monitoring guidelines. journal of American association gynecologic laparoscopists. 2000;7:167-168)," Journal of Minimally Invasive Gynecology, vol. 20, no. 2, pp. 137-148, 2013.

[48] M. Paschopoulos, N. P. Polyzos, L. G. Lavasidis, T. Vrekoussis, N. Dalkalitsis, and E. Paraskevaidis, "Safety issues of hysteroscopic surgery," Annals of the New York Academy of Sciences, vol. 1092, no. 1, pp. 229-234, 2006.

[49] M. M. Issa, "Technological advances in transurethral resection of the prostate: bipolar versus monopolar TURP," Journal of Endourology, vol. 22, no. 8, pp. 1587-1596, 2008. 
[50] American College of Obstetricians and Gynecologists, "Technology assessment no. 7: hysteroscopy," Obstetrics and Gynecology, vol. 117, no. 6, pp. 1486-1491, 2011.

[51] J. C. Ayus, D. Caputo, F. Bazerque, R. Heguilen, C. D. Gonzalez, and M. L. Moritz, "Treatment of hyponatremic encephalopathy with a $3 \%$ sodium chloride protocol: a case series," American Journal of Kidney Diseases: The Official Journal of the National Kidney Foundation, vol. 65, no. 3, pp. 435-442, 2015.

[52] G. Turato and S. Baraldo, "Hyponatremia in marathon runners," New England Journal of Medicine, vol. 353, no. 4, pp. 427-428, 2005.

[53] M. L. Moritz and J. C. Ayus, "The pathophysiology and treatment of hyponatraemic encephalopathy: an update," Nephrology Dialysis Transplantation, vol. 18, no. 12, pp. 2486-2491, 2003.

[54] American College of Obstetricians and Gynecologists, "ACOG technology assessment \#4: hysteroscopy," Obstetrics and Gynecology, vol. 106, no. 2, pp. 439-442, 2005. 